\title{
Common variants of SLAMF1 and ITLN1 on 1q21 are associated with type 2 diabetes in Indian population
}

\author{
Rubina Tabassum ${ }^{1}$, Anubha Mahajan ${ }^{1}$, Om Prakash Dwivedi ${ }^{1}$, Ganesh Chauhan ${ }^{1}$, Charles J Spurgeon ${ }^{2}$, \\ MV Kranthi Kumar ${ }^{2}$, Saurabh Ghosh ${ }^{3}$, SV Madhu ${ }^{4}$, Sandeep K Mathur ${ }^{5}$, Giriraj R Chandak ${ }^{2}$, Nikhil Tandon ${ }^{6}$ \\ and Dwaipayan Bharadwaj ${ }^{1}$
}

Though multiple studies link chromosomal regions 1q21-q23 and 20q13 with type 2 diabetes, fine mapping of these regions is yet to confirm gene(s) explaining the linkages. These candidate regions remain unexplored in Indians, which is a high-risk population for type 2 diabetes. Hypothesizing regulatory regions to have a more important role in complex disorders, we examined association of 207 common variants in proximal promoter and untranslated regions of genes on 1q21-23 and 20q13 with type 2 diabetes in 2115 North Indians. Further, top signals were replicated in an independent group of 2085 North Indians. Variants-rs11265455-SLAMF1 (odds ratios (OR) $\left.=1.32, P=1.1 \times 10^{-3}\right)$, rs1062827-F11R $\left(\mathrm{OR}=1.36, P=1.7 \times 10^{-3}\right)$ and $\mathrm{rs} 12565932-\mathrm{F} 11 R\left(\mathrm{OR}=1.35, P=1.8 \times 10^{-3}\right)$ were top signals for association with type 2 diabetes whereas rs 1333062 ITLN1 (OR=1.28, $P=3.4 \times 10^{-3}$ ) showed strongest association in body mass index-stratified analysis. Replication of these four variants confirmed associations of rs11265455-SLAMF1 (OR $\left.=1.27, P=9.1 \times 10^{-3}\right)$ and rs $1333062-$ ITLN1 $(O R=1.25$, $P=1.1 \times 10^{-3}$ ) with type 2 diabetes. Meta-analysis further corroborated the association of rs $11265455-$ SLAMF1 (OR random effect $=1.29, P$ random effect $=3.9 \times 10^{-5}$ ) and rs1333062-ITLN1 (OR random effect $=1.19, P$ random effect $=1.8 \times 10^{-4}$ ). In conclusion, the study demonstrates that variants of SLAMF1 and ITLN1, both implicated in inflammation, are associated with type 2 diabetes in Indians.

Journal of Human Genetics (2012) 57, 184-190; doi:10.1038/jhg.2011.150; published online 26 January 2012

Keywords: association; candidate regions; common variants; Indians; type 2 diabetes

\section{INTRODUCTION}

Type 2 diabetes is a complex metabolic disorder resulting from complex interaction of a large number of genetic and environmental factors. Linkage studies for type 2 diabetes have provided promising and replicated findings on $1 \mathrm{q} 21-\mathrm{q} 23^{1,2}$ and $20 \mathrm{q} 13 .^{3-7}$ These robust replications suggested the plausibility of localization of single or multiple susceptibility genes on these chromosomal regions. Subsequently, several studies performed fine mapping of these candidate regions but yielded little success. ${ }^{8}$ The extensive work of the $1 \mathrm{q} 21$ consortium found association of a few genes with type 2 diabetes on chromosome 1 but could not provide a confirmatory signal. ${ }^{8-10}$ Moreover, investigation of candidate genes on these regions have provided inconsistent and/or only modest association of a few genes

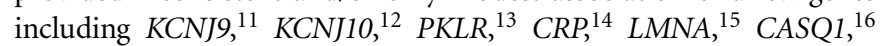
DUSP $12,{ }^{17}$ HNF $A,{ }^{18}{ }^{D O K 5}{ }^{19}$ and PTPN $11^{20}$ with type 2 diabetes. These candidate regions still remain unexplored in Indian population, which is a high-risk group for type 2 diabetes $^{21}$ that necessitates a systematic evaluation of these promising candidate regions in this population.

The associated genetic variants for complex disorders are expected to have moderate-to-small effects. This is evident from the findings of genome wide association studies on type 2 diabetes where majority of the variants identified till date have small-to-moderate effects and are located in non-coding regions. ${ }^{22}$ The same has also been observed for loci associated with different traits where $88 \%$ of the associated signals have moderate-to-weak effect and are located in non-coding regions. ${ }^{23}$ Interestingly, a recent study has shown abundance of heritable factors altering gene expression in trait-associated loci and suggested that genetic risk factors for complex traits often affect phenotype by altering gene expression..$^{24}$ This brings up a strong case for a focused study on regulatory variants with respect to complex traits. Comprehending this, we investigated association of 207 common variants in regulatory regions (proximal promoter, untranslated and flanking regions) of genes in type 2 diabetes-linked regions 1q21-23

${ }^{1}$ Genomics and Molecular Medicine Unit, CSIR-Institute of Genomics and Integrative Biology, Delhi, India; ${ }^{2}$ Genome Research Group, CSIR-Centre for Cellular and Molecular Biology, Hyderabad, India; ${ }^{3}$ Human Genetics Unit, Indian Statistical Institute, Kolkata, India; ${ }^{4}$ Division of Endocrinology, University College of Medical Sciences, Delhi, India; ${ }^{5}$ Department of Endocrinology, SMS Medical College and Hospital, Rajasthan, India and ${ }^{6}$ Department of Endocrinology, All India Institute of Medical Sciences, New Delhi, India Correspondence: N Tandon, Department of Endocrinology, All India Institute of Medical Sciences, Ansari Nagar, New Delhi- 110 029, India. E-mail: nikhil_tandon@hotmail.com or Dr D Bharadwaj, Genomics and Molecular Medicine Unit, CSIR-Institute of Genomics and Integrative Biology, Mall Road, Delhi- 110 007, India. E-mail: db@igib.res.in

Received 27 August 2011; revised 25 November 2011; accepted 11 December 2011; published online 26 January 2012 
and $20 \mathrm{q} 13$ with type 2 diabetes and its related traits in Indians in a two-stage case-control study.

\section{MATERIALS AND METHODS}

Subjects

Study involved participation of 4200 unrelated subjects of Indo-European ethnicity, recruited from urban regions in and around Delhi, North India. Initial association analysis was performed in 2115 subjects comprising 1073 patients with type 2 diabetes and 1042 controls. Replication was assessed in 2085 subjects of which 1047 were type 2 diabetes patients and 1038 were controls. Type 2 diabetes was diagnosed as per WHO (World Health Organization) criteria. ${ }^{25}$ Non-diabetic subjects of $\geqslant 40$ years without family history of diabetes who had glycated hemoglobin level $\leqslant 6.0 \%$ and fasting glucose level $<110 \mathrm{mg} \mathrm{dl}^{-1}$ were enrolled as controls. The inclusion and exclusion criteria for type 2 diabetes patients and control subjects are provided in details previously. ${ }^{26}$ Recruited subjects underwent extensive anthropometric and biochemical measurements as provided earlier, ${ }^{26}$ and their characteristics are presented in Table 1.

The study was carried out in accordance with the principles of Helsinki Declaration. The study was approved by the ethics committee of all the participating institutions (Institute of Genomics and Integrative Biology (CSIR), All India Institute of Medical Sciences, SMS Medical College and Hospital and University College of Medical Sciences). Informed written consent was obtained from all the participants.
Selection of genes and single nucleotide polymorphisms (SNPs) On 1q21-23, strongest linkage with type 2 diabetes had been observed at marker D1S484 with Lod-score of 5.3. ${ }^{27}$ We screened $2 \mathrm{Mb}$ genomic region around D1S484 spanning $158 \mathrm{Mb}-160 \mathrm{Mb}$ on chromosome 1 (NCBI build 36.3). On 20q13, $6 \mathrm{Mb}$ region around the strongest marker D20S196 (Lodscore 5.3), spanning $46 \mathrm{Mb}-52 \mathrm{Mb}$ (NCBI build 36.3) was explored because of low gene density. ${ }^{6}$ Information regarding all the genes within the regions was obtained from Ensembl database (v38) (http://www.ensembl.org/index.html). The $2 \mathrm{Mb}$ region of 1q21-23 had 59 genes whereas 37 genes were located within $6 \mathrm{Mb}$ region of $20 \mathrm{q} 13$.

Genes were searched for SNPs in 5'untranslated region , 3'untranslated region, $3 \mathrm{~kb}$ upstream and downstream of the genes, in NCBI variation database (dbSNP build 126: http://www.ncbi.nlm.nih. gov/SNP). SNPs in untranslated regions of the genes and tagSNPs were given preference, and at least one SNP in $5^{\prime}$ and $3^{\prime}$ regions for each gene was included, if available. A total of 207 SNPs comprising 131 SNPs of 59 genes from 1q21-23 and 76 SNPs of 37 genes from 20q13 (Supplementary Table 1) were genotyped in 2115 individuals in stage 1 (Supplementary Figures S1 and S2).

\section{Genotyping}

Genotyping in stage 1 was performed using Illumina GoldenGate assay (Illumina Inc., San Diego, CA, USA). Genotyping data were subjected to extensive quality control that included genotype confidence score $>0.25$, SNP call rate $>0.9$, GenTrans score $>0.6$, cluster separation score $>0.4$, Hardy Weinberg equilibrium $(P>0.05$ in controls), minor allele frequency $>0.05$.

Table 1 Anthropometric and clinical characteristics of the study populations

\begin{tabular}{|c|c|c|c|c|c|c|}
\hline \multirow[b]{2}{*}{ Characteristics } & \multicolumn{2}{|c|}{ Stage 1} & \multicolumn{2}{|c|}{ Stage 2} & \multirow[b]{2}{*}{$P^{a}$} & \multirow[b]{2}{*}{$P^{b}$} \\
\hline & Type 2 diabetic patients & Controls & Type 2 diabetic patients & Controls & & \\
\hline N (Men/women) & $1019(592 / 427)$ & $1006(606 / 400)$ & $1047(619 / 428)$ & $1038(516 / 522)$ & & \\
\hline Age (years) & $53(45-62)$ & $50(44-60)$ & $55(49-62)$ & $54(45-64)$ & $6 \times 10^{-4}$ & $6.3 \times 10^{-12}$ \\
\hline \multicolumn{7}{|l|}{$B M I\left(\mathrm{kgm}^{-2}\right)$} \\
\hline Women & $26.70(24.20-29.20)$ & 24.90 (21.10-28.60) & $27.20(24.40-30.50)$ & $26.40(23.10-29.40)$ & 0.002 & $3.5 \times 10^{-5}$ \\
\hline Men & $23.80(22.00-26.00)$ & $23.20(20.20-25.70)$ & $24.50(22.50-27.70)$ & $24.70(22.30-27.50)$ & $6.1 \times 10^{-9}$ & $2.2 \times 10^{-11}$ \\
\hline \multicolumn{7}{|l|}{ WC } \\
\hline Women & $91.44(86.36-96.52)$ & 85.00 (75.60-93.00) & $94.00(86.36-101.60)$ & $88.00(82.00-95.00)$ & 0.001 & $4.9 \times 10^{-5}$ \\
\hline Men & $86.36(86.36-91.44)$ & $88.50(80.64-95.00)$ & $93.00(86.36-101.60)$ & $93.00(87.00-101.00)$ & $4.9 \times 10^{-9}$ & $6.6 \times 10^{-17}$ \\
\hline \multicolumn{7}{|l|}{ WHR } \\
\hline Women & $1.00(0.97-1.03)$ & $0.86(0.82-0.92)$ & $0.93(0.87-0.97)$ & $0.86(0.82-0.90)$ & $6.8 \times 10^{-24}$ & 0.13 \\
\hline Men & $1.00(0.97-1.03)$ & $0.97(0.92-1.00)$ & $0.98(0.95-1.03)$ & $0.97(0.93-1.01)$ & 0.09 & 0.003 \\
\hline FPG $\left(\mathrm{mmol} \mathrm{I}^{-1}\right)$ & $7.90(6.40-10.30)$ & $4.90(4.50-5.30)$ & $7.79(6.21-10.27)$ & $4.87(4.43-5.27)$ & 0.6 & 0.38 \\
\hline $2 \mathrm{~h} \mathrm{PPG}\left(\mathrm{mmol} \mathrm{I}^{-1}\right)$ & - & $5.60(5.80-6.30)$ & - & $5.63(4.88-6.22)$ & - & 0.66 \\
\hline $\mathrm{HbA} 1 \mathrm{c}(\%)$ & $7.80(6.50-9.40)$ & $5.20(4.90-5.60)$ & $8.10(6.90-9.60)$ & $5.65(5.33-5.89)$ & $3.3 \times 10^{-4}$ & $2.1 \times 10^{-71}$ \\
\hline $\mathrm{FPI}\left(\mathrm{pmol} \mathrm{I}^{-1}\right)$ & - & $32.20(17.50-57.20)$ & - & $43.80(28.20-63.60)$ & - & $3.8 \times 10^{-16}$ \\
\hline HOMA IR & - & $1.16(0.59-2.02)$ & - & $1.60(1.00-2.40)$ & - & $8.2 \times 10^{-15}$ \\
\hline C-peptide (nmol I-1) & $0.89(0.56-1.36)$ & $0.53(0.36-0.73)$ & $1.05(0.69-1.60)$ & $0.66(0.50-0.86)$ & 0.002 & $3.6 \times 10^{-26}$ \\
\hline $\mathrm{hsCRP}\left(\mathrm{mg} \mathrm{l}^{-1}\right)$ & $2.20(0.90-4.70)$ & $1.30(0.60-3.00)$ & $1.86(0.90-3.44)$ & $1.61(0.90-3.04)$ & 0.27 & $1.4 \times 10^{-6}$ \\
\hline $\mathrm{TC}\left(\mathrm{mmoll}^{-1}\right)$ & $4.20(3.50-5.00)$ & $4.40(3.70-5.10)$ & $4.64(3.86-5.42)$ & $4.91(4.22-5.52)$ & $1.8 \times 10^{-12}$ & $1.1 \times 10^{-26}$ \\
\hline $\mathrm{HDL}-\mathrm{C}\left(\mathrm{mmol} \mathrm{I}^{-1}\right)$ & $1.03(0.88-1.22)$ & $1.06(0.88-1.28)$ & $1.11(0.94-1.34)$ & $1.24(1.06-1.46)$ & $1.6 \times 10^{-9}$ & $2.8 \times 10^{-36}$ \\
\hline LDL-C (mmol I-1) & 2.57 (1.99-3.36) & $2.79(2.33-3.41)$ & $2.73(2.10-3.42)$ & $3.01(2.49-3.51)$ & 0.02 & $2.9 \times 10^{-7}$ \\
\hline $\mathrm{TG}\left(\mathrm{mmol} \mathrm{I}^{-1}\right)$ & $1.60(1.10-2.20)$ & $1.30(1.00-1.80)$ & $1.43(0.98-2.13)$ & $1.22(0.86-1.64)$ & $6 \times 10^{-4}$ & $2.9 \times 10^{-7}$ \\
\hline Systolic BP (mm Hg) & $130(130-140)$ & $120(112-133)$ & $130(122-140)$ & $130(120-140)$ & $2.9 \times 10^{-5}$ & $1.5 \times 10^{-6}$ \\
\hline Diastolic BP (mm Hg) & $80(78-90)$ & $80(70-88)$ & $82(80-90)$ & $80(78-90)$ & $1.5 \times 10^{-5}$ & $7.1 \times 10^{-14}$ \\
\hline
\end{tabular}

Abbreviations: BMI, body mass index; BP, blood pressure; FPG, fasting plasma glucose; FPI, fasting plasma insulin; HbAlc, glycosylated hemoglobin Alc; HDL-C, high-density lipoprotein cholesterol; HOMA-IR, homeostasis model assessment for insulin resistance; hsCRP, high sensitivity C-reactive protein; LDL-C, low-density lipoprotein cholesterol; TG, triglycerides; TC, total cholesterol; WC, waist circumference; WHR, waist-to-hip ratio; $2 \mathrm{~h}$ PPG, $2 \mathrm{~h}$ post-prandial glucose.

Data are presented as median (interquartile range).

aDifference in medians of the quantitative trait values of type 2 diabetes patients in stage 1 and stage 2 (Mann-Whitney $U$ test).

bifference in medians of the quantitative trait values of controls in stage 1 and stage 2 (Mann-Whitney $U$ test). 
Ninety samples had genotype call for $<90 \%$ of the SNPs and were excluded from the analysis. A total of 150 SNPs were available for further analysis, having average call rate of $99.5 \%$, with concordance of $>99.9 \%$ in genotype calls in $7 \%$ duplicates.

In stage 2 for replication, four top signals from stage 1: rs11265455 (SLAMF1), rs1062827 (F11R), rs12565932 (F11R) and rs1333062 (ITLN1) were genotyped using iPLEX (Sequenom, San Deigo, CA, USA). Average genotyping success rate was $96 \%$ with $>99.8 \%$ consistency rate in genotype calls in $5 \%$ duplicates.

\section{Statistical analysis}

Statistical analyses were mainly performed using PLINK v. 1.07 (http://www. pngu.mgh.harvard.edu/purcell/plink/). Hardy Weinberg equilibrium was tested using $\chi^{2}$ analyses. Association of SNPs with type 2 diabetes was assessed using logistic regression under additive model adjusted for age, sex and body mass index (BMI). Odds ratios (ORs) were calculated with respect to risk allele. Meta-analysis was performed by combining summary estimates both under random effect and fixed effect models. $P$ value $<3.3 \times 10^{-4}$ was considered significant after multiple testing correction for independent SNPs $(0.05 / 138)$. Association of SNPs with quantitative traits was determined using linear regression adjusted for age, sex and BMI as appropriate, in control subjects after inverse normal transformation of the data to achieve normal distribution. A $P$ value $<2.0 \times 10^{-5}(0.05 /(17 \times 138))$ was considered significant after multiple testing correction for quantitative traits analysis. Statistical power of the study was estimated using QUANTO version 1.2 (http://hydra.usc.edu/gxe/). ${ }^{28}$ Our sample size in the initial phase had $70-97 \%$ power to detect the association with OR of 1.3-1.5 assuming minor allele frequency of 0.20 .

\section{RESULTS}

On 1q21-23, 10 SNPs showed association with type 2 diabetes $(P<0.05)$, with most significant association at rs11265455 in $5^{\prime}$ flank of SLAMF1 $\left(\mathrm{OR}=1.32, P=1.1 \times 10^{-3}\right)$. The highest $\mathrm{OR}$ was obtained for $3^{\prime}$ untranslated region variants (rs1062827 and rs12565932) of F11R (OR=1.36, $P=1.5 \times 10^{-3}$ and 1.35, $P=1.8 \times 10^{-3}$ ) (Table 2 ). On $20 \mathrm{q} 13$, only nominal associations at rs5602 (PTGIS) was observed $(P=0.026)$. Allelic and genotypic distributions of all the SNPs investigated for association with type 2 diabetes are provided in Supplementary Table 1.

As obesity status is shown to modulate genetic susceptibility of type 2 diabetes previously, ${ }^{26,29}$ we performed BMI-stratified association analysis after segregating subjects as normal-weight $\left(\mathrm{BMI}<23 \mathrm{~kg} \mathrm{~m}^{-2}\right)$ and overweight/obese $\left(\mathrm{BMI} \geqslant 23 \mathrm{~kg} \mathrm{~m}^{-2}\right) \cdot{ }^{30}$ The most significant association was found at $\mathrm{rs} 881291$ of ATP1A4 (OR=1.42, $P=3.8 \times 10^{-3}$ ) on $1 \mathrm{q} 21-23$ in normal-weight subjects and at rs1333062 of ITLN1 $\left(\mathrm{OR}=1.28, P=3.4 \times 10^{-3}\right)$ in overweight/obese subjects (Supplementary Table 2). Interestingly, the association of rs1333062 (ITLN1) in BMI-stratified analysis was found to be stronger than the entire data set.

For replication analysis, we selected SNPs rs11265455, rs1062827 and rs12565932, which showed association with type 2 diabetes at $P<5.0 \times 10^{-3}$. In addition, we also selected an interesting signal rs1333062 that was nominally associated in entire data set $(P=0.039)$ but showed stronger association with type 2 diabetes in BMI-stratified analysis $\left(P<5.0 \times 10^{-3}\right)$. Associations of rs11265455 in SLAMF1 and rs1333062 in ITLN1 were confirmed in replication analyses that were corroborated by the meta-analysis of two study populations $\left(\mathrm{OR}^{\mathrm{r}}=1.29, P^{r}=3.9 \times 10^{-5}\right.$ and $\mathrm{OR}^{\mathrm{r}}=1.19, P^{\mathrm{r}}=1.8 \times 10^{-4}$, respectively) (Table 2 ). Association of both the variants remained significant after correcting for multiple tests. As observed in stage 1, we found stronger association of ITLN1 variant rs1333062 with type 2 diabetes among overweight/obese subjects in BMI-stratified analyses in stage $2\left(\mathrm{OR}=1.28 P=7.8 \times 10^{-3}\right)$ and meta-analysis $\left(\mathrm{OR}^{\mathrm{r}}=1.25\right.$, $\left.P^{r}=8.8 \times 10^{-5}\right)($ Table 3$)$. The combined analysis also showed significant association of rs1333062 with type 2 diabetes among overweight/ obese subjects $\left(\mathrm{OR}=1.25, P=8.7 \times 10^{-5}\right)$. For F11R SNPs rs12565932 and rs1062827, only nominal association under fixed effect model of meta-analysis was observed $\left(\mathrm{OR}^{\mathrm{f}}=1.19\right.$ and $1.18, \mathrm{f}^{\mathrm{f}}=0.011$ and 0.016 , respectively). Similar results were obtained when the analysis was performed by combining the raw genotyping data from two stages (Table 2).

We investigated the functional effects of SLAMF1 and ITLN1 variants through cis-gene expression quantitative trait loci (cis-eQTL) analysis using transcriptome data from University of Chicago's eQTL data repository (http://www.eqtl.uchicao.edu/cgibin/gbrowse/eqtl). The ITLN1 variant rs1333062 is in strong linkage disequilibrium (LD) with $\mathrm{rs} 11265519\left(r^{2}=0.89\right)$, which is shown to be associated with the expression of $L Y 9\left(P=2.4 \times 10^{-7}\right)$, C4ORF11 $\left(P=1.7 \times 10^{-6}\right)$, AF009262 $\left(P=2.9 \times 10^{-6}\right)$, OR5B21 $\left(P=1.0 \times 10^{-6}\right)$, $\operatorname{IGSF} 4 B\left(P=5.0 \times 10^{-4}\right)$ and SLAMF8 $\left(P=3.6 \times 10^{-3}\right)$ in liver. We found an eQTL rs7550771 near SLAMF1, but this eQTL was not in LD with the associated variant rs11265455.

Table 2 Association of SNPs on 1q21-23 and 20q13 with type 2 diabetes in North Indian population

\begin{tabular}{|c|c|c|c|c|c|c|c|c|c|c|c|c|}
\hline \multirow[b]{3}{*}{$\begin{array}{l}\text { SNP } \\
\text { (Gene) }\end{array}$} & \multicolumn{3}{|c|}{ Stage 1} & \multicolumn{3}{|c|}{ Stage 2} & \multicolumn{2}{|c|}{ Combined analysis } & \multicolumn{4}{|c|}{ Meta-analysis } \\
\hline & $R A F$ & & & $R A F$ & & & & & & $\mathrm{P}^{r}$ & & \\
\hline & $\begin{array}{c}\text { Cases } \\
\text { Controls }\end{array}$ & $\begin{array}{c}\text { OR } \\
(95 \% C l)\end{array}$ & $\mathrm{P}$ & $\begin{array}{c}\text { Cases } \\
\text { Controls }\end{array}$ & $\begin{array}{c}\text { OR } \\
(95 \% C l)\end{array}$ & $\mathrm{P}$ & $\begin{array}{c}\text { OR } \\
(95 \% \mathrm{Cl})\end{array}$ & $\mathrm{P}$ & $\begin{array}{l}O R^{r} \\
O R^{f}\end{array}$ & $\begin{array}{l}\mathrm{P} \\
f\end{array}$ & $Q$ & 1 \\
\hline rs11265455 (A/G) & 0.199 & 1.32 & $1.1 \times 10^{-3}$ & 0.173 & 1.27 & $9.1 \times 10^{-3}$ & 1.31 & $1.6 \times 10^{-5}$ & 1.29 & $3.9 \times 10^{-5}$ & 0.826 & 0.0 \\
\hline$(S L A M F 1)$ & 0.158 & $(1.12-1.56)$ & & 0.140 & $(1.06-1.52)$ & & $(1.16-1.47)$ & & 1.29 & $3.9 \times 10^{-5}$ & & \\
\hline rs1333062 (G/T) & 0.402 & 1.15 & 0.032 & 0.387 & 1.25 & $1.1 \times 10^{-3}$ & 1.19 & $1.9 \times 10^{-4}$ & 1.19 & $1.8 \times 10^{-4}$ & 0.360 & 0.0 \\
\hline (ITLN1) & 0.373 & $(1.01-1.32)$ & & 0.340 & (1.09-1.43) & & $(1.09-1.31)$ & & 1.19 & $1.8 \times 10^{-4}$ & & \\
\hline rs1062827 (G/A) & 0.887 & 1.36 & $1.7 \times 10^{-3}$ & 0.884 & 1.02 & 0.810 & 1.17 & 0.023 & 1.18 & 0.245 & 0.037 & 76.9 \\
\hline$(F 11 R)$ & 0.855 & $(1.13-1.65)$ & & 0.880 & $(0.85-1.23)$ & & $(1.02-1.33)$ & & 1.18 & 0.016 & & \\
\hline rs12565932 (T/C) & 0.887 & 1.35 & $1.8 \times 10^{-3}$ & 0.885 & 1.05 & 0.638 & 1.18 & 0.015 & 1.19 & 0.173 & 0.063 & 71.0 \\
\hline$(F 11 R)$ & 0.855 & $(1.12-1.64)$ & & 0.879 & $(0.65-1.26)$ & & $(1.03-1.35)$ & & 1.19 & 0.011 & & \\
\hline
\end{tabular}

Abbreviations: I, $I^{\wedge} 2$ heterogeneity index (0-100); OR ${ }^{\dagger}$, odds ratio for fixed-effects meta-analysis; OR ${ }^{r}$, odds ratio for random-effects meta-analysis; $P^{f}, P$ value for fixed-effects meta-analysis; $P$, $P$ value for random-effects meta-analysis; RAF, risk allele frequency; $Q, P$ value for Cochrane's $Q$ statistic.

Combined analysis was done by combining raw genotype data from stage 1 and stage 2 .

Meta-analysis was performed by combining the summary estimates (OR, $95 \% \mathrm{Cl})$. 
Table 3 BMI-stratified analysis of SNPs associated with type 2 diabetes in North Indians

\begin{tabular}{|c|c|c|c|c|c|c|c|c|c|c|}
\hline \multirow[b]{2}{*}{ SNP (Gene) } & \multicolumn{2}{|l|}{ Stage 1} & \multicolumn{2}{|l|}{ Stage 2} & \multicolumn{2}{|c|}{ Combined analysis } & \multicolumn{4}{|c|}{ Meta-analysis } \\
\hline & OR $(95 \% \mathrm{Cl})$ & $P$ & OR $(95 \% \mathrm{Cl})$ & $P$ & OR $(95 \% \mathrm{Cl})$ & $P$ & $O R^{r} / O R^{f}$ & $P^{r} / P^{f}$ & $Q$ & 1 \\
\hline \multicolumn{11}{|c|}{ Normal-weight subjects (284 patients; 446 controls) } \\
\hline rs11265455 (A/G) & $1.31(1.00-1.71)$ & 0.050 & $1.43(1.01-2.04)$ & 0.046 & $1.35(1.09-1.67)$ & $5.4 \times 10^{-3}$ & $1.35 / 1.35$ & $5.7 \times 10^{-3} / 5.7 \times 10^{-3}$ & 0.688 & 0.0 \\
\hline rs1333062 (G/T) & $0.97(0.78-1.20)$ & 0.778 & $1.29(0.99-1.69)$ & 0.062 & $1.08(0.92-1.28)$ & 0.349 & $1.11 / 1.08$ & $0.482 / 0.346$ & 0.103 & 62.5 \\
\hline rs1062827 (G/A) & $1.37(0.97-1.93)$ & 0.070 & $1.31(0.89-1.92)$ & 0.167 & $1.34(1.04-1.73)$ & 0.023 & $1.34 / 1.34$ & $0.023 / 0.023$ & 0.863 & 0.0 \\
\hline \multicolumn{11}{|c|}{ Overweight/obese subjects (665 patients; 588 controls) } \\
\hline rs11265455 (A/G) & $1.31(1.06-1.62)$ & 0.012 & $1.24(1.01-1.53)$ & 0.045 & $1.30(1.12-1.50)$ & $6.5 \times 10^{-4}$ & $1.27 / 1.27$ & $1.4 \times 10^{-3} / 1.4 \times 10^{-3}$ & 0.715 & 0.0 \\
\hline rs1333062 (G/T) & $1.28(1.09-1.52)$ & $3.4 \times 10^{-3}$ & $1.23(1.06-1.44)$ & $7.8 \times 10^{-3}$ & $1.25(1.12-1.41)$ & $8.7 \times 10^{-5}$ & $1.26 / 1.26$ & $8.2 \times 10^{-5} / 8.2 \times 10^{-5}$ & 0.727 & 0.0 \\
\hline rs1062827 (G/A) & $1.35(1.07-1.70)$ & 0.011 & $0.93(0.75-1.16)$ & 0.541 & $1.10(0.94-1.29)$ & 0.242 & $1.12 / 1.11$ & $0.537 / 0.192$ & 0.023 & 80.6 \\
\hline rs12565932 (T/C) & $1.34(1.06-1.68)$ & 0.013 & $0.96(0.77-1.19)$ & 0.711 & $1.11(0.95-1.30)$ & 0.196 & $1.13 / 1.12$ & $0.460 / 0.152$ & 0.040 & 76.3 \\
\hline
\end{tabular}

Abbreviations: I, I^2 heterogeneity index (0-100); OR ${ }^{\dagger}$, odds ratio for fixed-effects meta-analysis; OR', odds ratio for random-effects meta-analysis; $P^{f}, P$ value for fixed-effects meta-analysis; $P$, $P$ value for random-effects meta-analysis; RAF, risk allele frequency; $Q, P$ value for Cochrane's $Q$ statistic.

Combined analysis was done by combining raw genotype data from stage 1 and stage 2 .

Meta-analysis was performed by combining the summary estimates (OR, $95 \% \mathrm{Cl}$ and s.e).

Next, we investigated association of SNPs with metabolic traits that are risk factors for type 2 diabetes, including obesity (waist circumference, hip circumference, waist-to-hip ratio), glucose homeostasis (fasting plasma glucose, glycated hemoglobin, fasting plasma insulin, C-peptide, homeostasis model assessment of insulin resistance (HOMA-IR)), dyslipidemia (total cholesterol, triglyceride, high-density lipoprotein cholesterol, low-density lipoprotein cholesterol) and inflammation (high sensitivity C-reactive protein) (Figures 1 and 2). For obesity-related phenotypes, strongest signal for association was observed at rs 1008687 of SPATA2 $\left(\beta=-1.13 \mathrm{~kg} \mathrm{~m}^{-2}, P=3.4 \times 10^{-5}\right.$ for BMI) on $20 \mathrm{q} 13$ (Figure 2$)$. We also found association of rs1008687 with HOMA-IR and fasting plasma insulin. The strongest association with measures of glucose homeostasis was observed at rs 16858733 of FCRLB on 1q21-23 $\left(P=3.3 \times 10^{-4}\right.$ for fasting plasma glucose, $P=2.5 \times 10^{-3}$ for fasting plasma insulin and $P=3.1 \times 10^{-4}$ for HOMA-IR). SNPs showing putative association with quantitative clinical traits are listed in Supplementary Table 3.

\section{DISCUSSION}

Investigation of genetic risk factors for type 2 diabetes in Indians, which is the high-risk group for type 2 diabetes and related metabolic traits, is very imperative. However, efforts on these lines are very limited, often restricted to replication of genome wide association studies findings. Taking lead from genome wide linkage scans, many studies investigated the association of genetic variants from linked 1q21 region with type 2 diabetes in European populations; however, there have been no such efforts from India. The present study was designed to explore high-risk Indian population for type 2 diabetes genetic risk factors from two of the strongly linked chromosomal regions $1 \mathrm{q} 21-23$ and $20 \mathrm{q} 13$.

We demonstrate association of common variants of SLAMF1 and ITLN1 on 1q21-23 with type 2 diabetes. SLAMF1 encodes signaling lymphocytic activation molecule family member 1 (SLAMF1), also called as CD150. Expression of SLAMF1 is shown to be raised on peripheral blood B cells and synovial fluid from patients with rheumatoid arthritis. ${ }^{31}$ Here, we found association of rs11265455 in proximal region of SLAMF1 with type 2 diabetes. ITLN1 encodes Intelectin 1 (Omentin 1), an adipokine that enhances insulin-stimu- lated glucose uptake in adipocytes. ${ }^{32}$ Plasma levels of Intelectin 1 are inversely correlated with BMI, waist circumference and insulin resistance. $^{33}$ A study that investigated association of Val109Asp variant of ITLN1 with type 2 diabetes in Caucasians failed to detect the same. ${ }^{34}$ On contrary, our analysis revealed association of rs1333062 in $3^{\prime}$ flank region of ITLN1, which is in complete LD with Val109Asp of ITLN1 $\left(\mathrm{D}^{\prime}=1.0\right.$ and $r^{2}=1.0$ both for GIH (Gujarati Indians in Houston, Texas) and CEU (Utah residents with Northern and Western European ancestry from the CEPH collection) populations from HapMap data). The observed association of rs1333062 might reflect functional consequence of the missense variant in LD in type 2 diabetes. Moreover, eQTL analysis showed that rs1333062 is in strong LD with rs11265519, which is associated with the expression of nearby genes including $L Y 9, I G S F 4 B$ and SLAMF8 in liver. These evidences support our findings that suggest ITLN1 as a susceptibility locus for type 2 diabetes.

Suggestive associations of variants of F11R were also observed in initial analysis, but could not be replicated. Previous reports of association of F11R variants with hypertension and obesity ${ }^{35}$ support our observations. Also, meta-analysis corroborated our initial findings, but the inconsistency in stagel and stage 2 warrants further investigation of these variants in other populations. We also identified genomic segments on 1q21-23 and 20q13 influencing type 2 diabetesrelated traits, such as obesity, glucose homeostasis and dyslipidemia, which may further be fine mapped to find susceptibility genes for these intermediate phenotypic traits. Notably, we have reported all potential associations of SNPs with metabolic traits at nominal significance $(P<0.05)$. Though increasing the likelihood of false-positive associations, this might provide lead for further investigations of these regions in other populations.

Investigated chromosomal regions harbors a number of positional candidate genes including APOA2, DUSP12, ATF6, KCNJ9 and KCNJ10. Consistent with earlier association of DUSP12 variant with glucose in Chinese population, ${ }^{36}$ we also found similar result in North Indians. Contradictory results regarding association of ATF6 with type 2 diabetes have been reported earlier. ${ }^{37-39}$ Our study detected nominal association of an ATF6 variant with type 2 diabetes and BMI. PTPN1 is shown as an important contributor to risk of type 2 diabetes, obesity and metabolic syndrome; ${ }^{20}$ however, no association could be observed in our population. APOA2, KCNJ9 and 

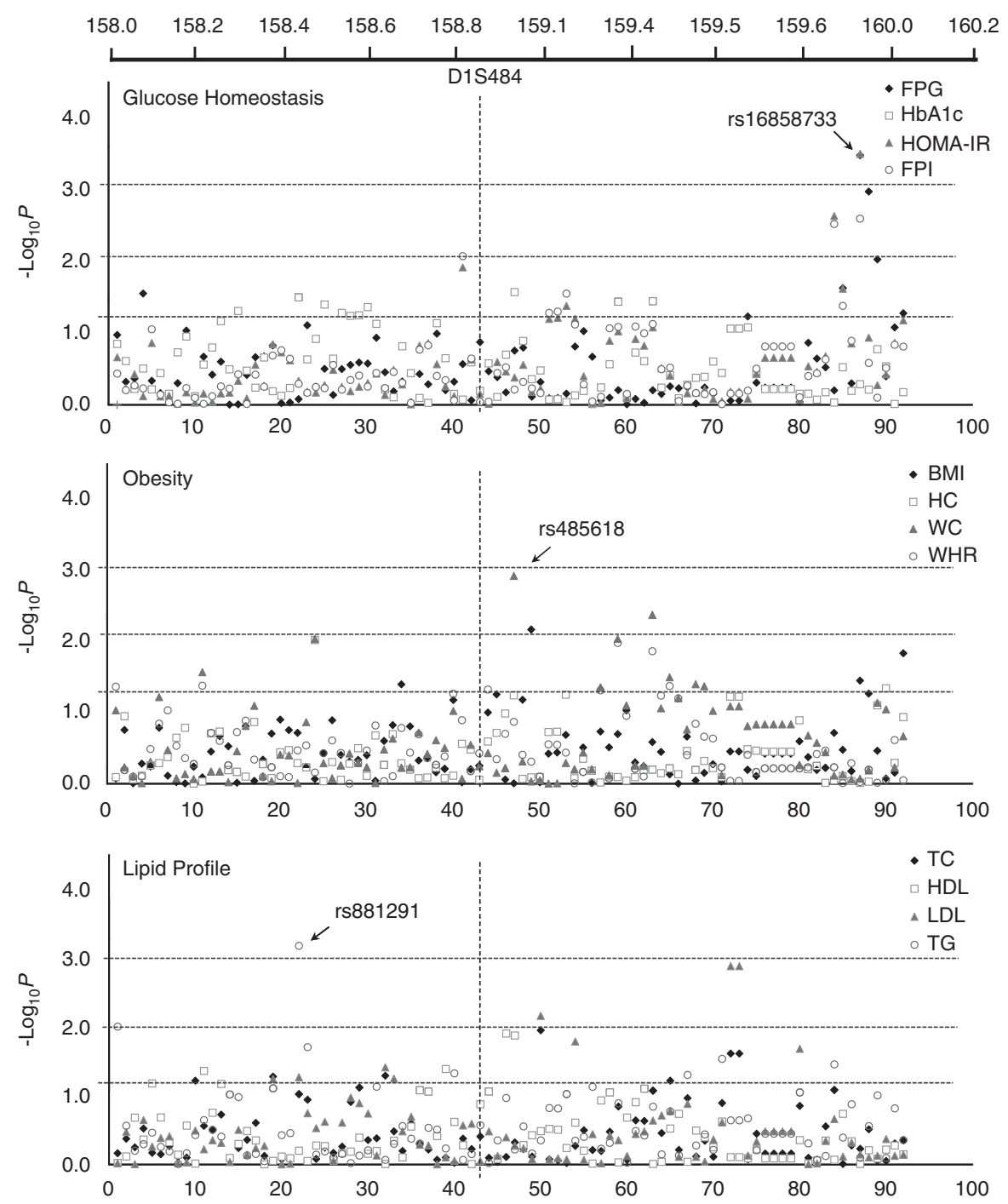

Figure 1 Association of SNPs on 1q21-23 with type 2 diabetes-related clinical traits. Legend: The $-\log _{10} P$ values are plotted against the chromosomal location (NCBI build 36.3). A full color version of this figure is available at the Journal of Human Genetics journal online.

KCNJ10, the well-known biological candidates for type 2 diabetes, did not show any association with type 2 diabetes or any related trait in our study.

Given the scope of the present study, investigation of the selected candidate regions is restricted only to the smaller regions of observed linkage, which generally extend to $\sim 10 \mathrm{Mb}$. Here we adopted a gene-centric approach and focused on the regulatory regions of the genes located on these candidate loci. The role of coding variants in complex disorders cannot be ruled out, but the present knowledge and evidences suggest more likelihood of regulatory variants being involved in complex diseases. With the power of the study, we expected higher likelihood of finding association in putative regulatory regions and hence, mainly focused on those variants. Thus, further investigation of the identified genes for variants in coding and intronic regions is required to establish their etiologic role, if any. Moreover, we would like to mention that though using the present approach we identified association of two genes with type 2 diabetes, further examination of tag SNPs that provide better coverage of the variations in the candidate regions might facilitate identification of additional susceptibility variants.

A study by Rosenberg, et al. ${ }^{40}$ stated that false-positives due to genetic heterogeneity in diverse Indian population could be smaller than expected. Still, we made considerable efforts to avoid population stratification by recruiting subjects in both the phases with great caution with regards to their ethnicity and geographical regions, forming a homogenous cluster as reported by the Indian Genome Variation Consortium. ${ }^{41}$ The multidimensional scaling based on 608 unlinked markers genotyped in our initial study population also clearly shows that the study population belongs to one cluster (Supplementary Figure S3).

In conclusion, the present study demonstrates association of common variants of SLAMF1 and ITLN1 with type 2 diabetes in North Indians. Further studies validating the association of these variants in our populations and exploring functional significance are warranted. 

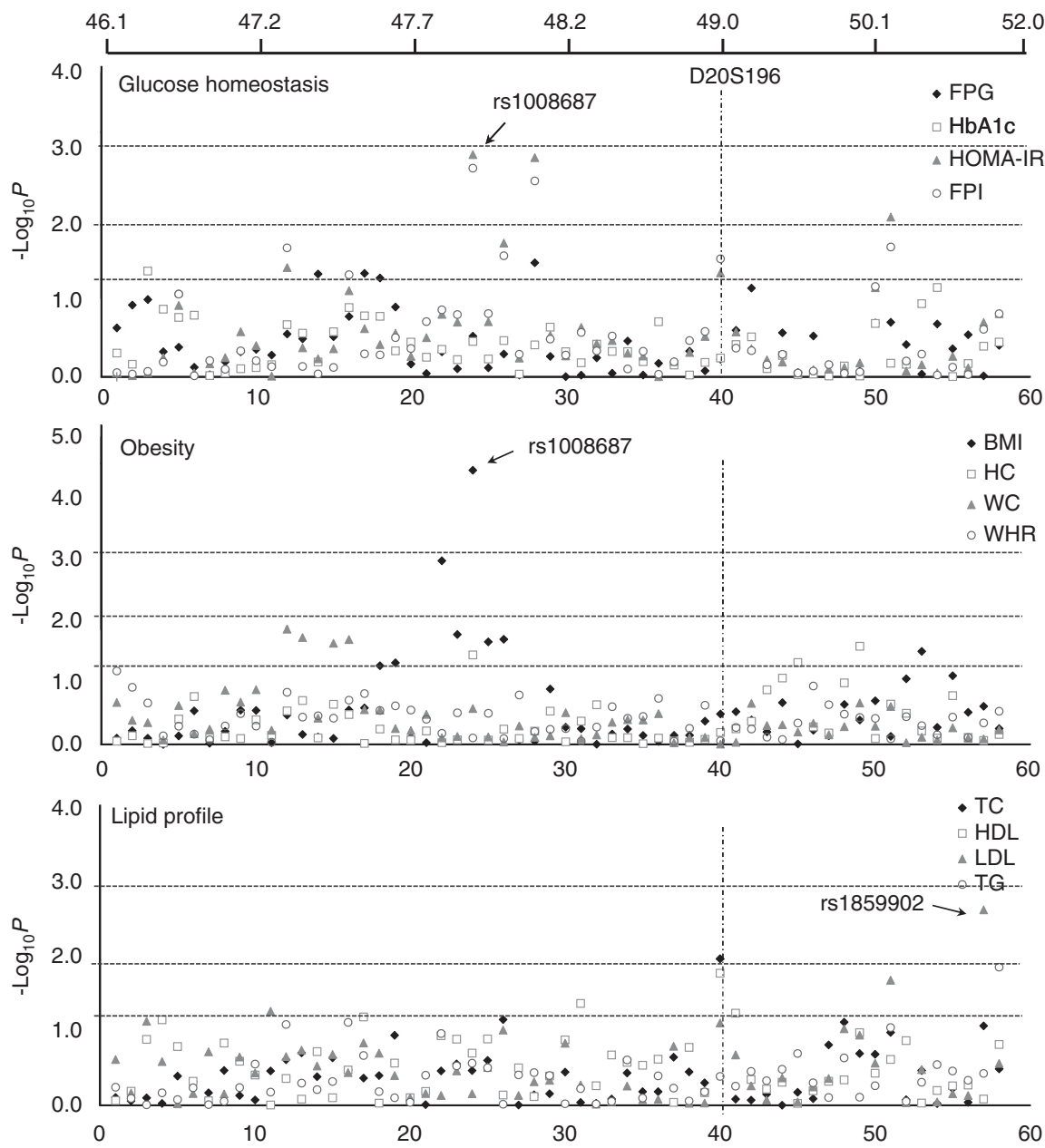

Figure 2 Association of SNPs on 20q13 with type 2 diabetes-related clinical traits. Legend: The $-\log _{10} P$ values are plotted against the chromosomal location (NCBI build 36.3). A full color version of this figure is available at the Journal of Human Genetics journal online.

\section{CONFLICT OF INTEREST}

The authors declare no conflicts of interest.

\section{ACKNOWLEDGEMENTS}

This study was supported by 'Diabetes mellitus-New drug discovery R\&D, molecular mechanisms and genetic \& epidemiological factors' (NWP0032-10) funded by Council of Scientific and Industrial Research (CSIR), Government of India. We are thankful to all the patients and healthy individuals for their participation in the study. We also thank Mr AK Sharma for his help in sample collection. We thank Dr Abhay Sharma (Institute of Genomics and Integrative Biology, CSIR) for the critical evaluation of the manuscript.

1 McCarthy, M. I. Growing evidence for diabetes susceptibility genes from genome scan data. Curr. Diab. Rep. 3, 159-67 (2003).

2 Das, S. K. \& Elbein, S. C. The search for type 2 diabetes susceptibility loci: the chromosome 1q story. Curr. Diab. Rep. 7, 154-164 (2007).

3 Ji, L., Malecki, M., Warram, J. H., Yang, Y., Rich, S. S. \& Krolewski, A. S. New susceptibility locus for NIDDM is localized to human chromosome 20q. Diabetes 46, 876-881 (1997).

4 Bowden, D. W., Sale, M., Howard, T. D., Qadri, A., Spray, B. J., Rothschild, C. B. et al. Linkage of genetic markers on human chromosomes 20 and 12 to NIDDM in Caucasian sib pairs with a history of diabetic nephropathy. Diabetes 46, 882-886 (1997).

5 Zouali, H., Hani, E. H., Philippi, A., Vionnet, N., Beckmann, J. S., Demenais, F. et al. A susceptibility locus for early-onset non-insulin dependent (type 2) diabetes mellitus maps to chromosome 20q, proximal to the phosphoenolpyruvate carboxykinase gene. Hum. Mol. Genet. 6, 1401-1408 (1997).

6 Klupa, T., Malecki, M. T., Pezzolesi, M., Ji, L., Curtis, S., Langefeld, C. D. et al. Further evidence for a susceptibility locus for type 2 diabetes on chromosome 20q13.1-q13.2. Diabetes 49, 2212-2216 (2000).

7 Rotimi, C. N., Chen, G., Adeyemo, A. A., Furbert-Harris, P., Parish-Gause, D., Zhou, J. et al. A genome-wide search for type 2 diabetes susceptibility genes in West Africans: the Africa America Diabetes Mellitus (AADM) Study. Diabetes 53, 838-841 (2004).

8 Prokopenko, I., Zeggini, E., Hanson, R. L., Mitchell, B. D., Rayner, N. W., Akan, P. et al. Linkage disequilibrium mapping of the replicated type 2 diabetes linkage signal on chromosome 1q. Diabetes 58, 1704-1709 (2009).

9 Ma, L., Hanson, R. L., Que, L. N., Cali, A. M., Fu, M., Mack, J. L. et al. Variants in ARHGEF11, a candidate gene for the linkage to type 2 diabetes on chromosome 1q, are nominally associated with insulin resistance and type 2 diabetes in Pima Indians. Diabetes 56, 1454-1459 (2007).

$10 \mathrm{Hu}$, C., Wang, C., Zhang, R., Ng, M. C., Bao, Y., Wang, C. et al. Association of genetic variants of NOS1AP with type 2 diabetes in a Chinese population. Diabetologia 53, 290-298 (2010).

11 Wolford, J. K., Hanson, R. L., Kobes, S., Bogardus, C. \& Prochazka, M. Analysis of linkage disequilibrium between polymorphisms in the KCNJ9 gene with type 2 diabetes mellitus in Pima Indians. Mol. Genet. Metab. 73, 97-103 (2001).

12 Farook, V. S., Hanson, R. L., Wolford, J. K., Bogardus, C. \& Prochazka, M. Molecular analysis of $\mathrm{KCNJ} 10$ on $1 \mathrm{q}$ as a candidate gene for Type 2 diabetes in Pima Indians. Diabetes 51, 3342-3346 (2002).

13 Wang, H., Chu, W., Das, S. K., Ren, Q., Hasstedt, S. J. \& Elbein, S. C. Liver pyruvate kinase polymorphisms are associated with type 2 diabetes in northern European Caucasians. Diabetes 51, 2861-2865 (2002).

14 Wolford, J. K., Gruber, J. D., Ossowski, V. M., Vozarova, B., Antonio Tataranni, P., Bogardus, C. et al. A C-reactive protein promoter polymorphism is associated with type 2 diabetes mellitus in Pima Indians. Mol. Genet. Metab. 78, 136-144 (2003).

15 Wegner, L., Andersen, G., Sparso, T., Grarup, N., Glümer, C., Borch-Johnsen, K et al. Common variation in LMNA increases susceptibility to type 2 diabetes 
and associates with elevated fasting glycemia and estimates of body fat and height in the general population: studies of 7495 Danish whites. Diabetes 56, 694-698 (2007).

16 Fu, M., Damcott, C. M., Sabra, M., Pollin, T. I., Ott, S. H., Wang, J. et al. Polymorphism in the calsequestrin 1 (CASQ1) gene on chromosome 1q21 is associated with type 2 diabetes in the old order Amish. Diabetes 53, 3292-3299 (2004).

17 Das, S. K., Chu, W. S., Hale, T. C., Wang, X., Craig, R. L., Wang, H. et al. Polymorphisms in the glucokinase-associated, dual-specificity phosphatase 12 (DUSP12) gene under chromosome 1q21 linkage peak are associated with type 2 diabetes. Diabetes 55, 2631-2639 (2006).

18 Barroso, I., Luan, J., Wheeler, E., Whittaker, P., Wasson, J., Zeggini, E. et al. Population-specific risk of type 2 diabetes conferred by HNF4A P2 promoter variants: a lesson for replication studies. Diabetes 57, 3161-3165 (2008).

19 Tabassum, R., Mahajan, A., Chauhan, G., Dwivedi, O. P., Ghosh, S., Tandon, N. et al. Evaluation of DOK5 as a susceptibility gene for type 2 diabetes and obesity in North Indian population. BMC Med. Genet. 11, 35 (2010).

20 Bento, J. L., Palmer, N. D., Mychaleckyj, J. C., Lange, L. A., Langefeld, C. D., Rich, S. S. et al. Association of protein tyrosine phosphatase $1 \mathrm{~B}$ gene polymorphisms with type 2 diabetes. Diabetes 53, 3007-3012 (2004).

21 Wild, S., Roglic, G., Green, A., Sicree, R. \& King, H. Global prevalence of diabetes: estimates for the year 2000 and projections for 2030. Diabetes Care 27, 1047-1053 (2004).

22 McCarthy, M. I. Genomics, type 2 diabetes, and obesity. N. Engl. J. Med. 363, 2339-2350 (2010)

23 Hindorff, L. A., Sethupathy, P., Junkins, H. A., Ramos, E. M., Mehta, J. P., Collins, F. S. et al. Potential etiologic and functional implications of genome-wide association loci for human diseases and traits. Proc. Natl. Acad. Sci. 106, 9362-9367 (2009).

24 Nicolae, D. L., Gamazon, E., Zhang, W., Duan, S., Dolan, M. E. \& Cox, N. J. Traitassociated SNPs are more likely to be eQTLs: annotation to enhance discovery from GWAS. PLoS Genet. 6, e1000888 (2010).

25 Expert Committee on the Diagnosis and Classification of Diabetes Mellitus.. Report of the expert committee on the diagnosis and classification of diabetes mellitus. Diabetes Care 26, S5-S20 (2003).

26 Tabassum, R., Chavali, S., Dwivedi, O. P., Tandon, N. \& Bharadwaj, D. Genetic variants of FOXA2: risk of type 2 diabetes and effect on metabolic traits in North Indians. J. Hum. Genet. 53, 957-965 (2008).

27 Das, S. K., Hasstedt, S. J., Zhang, Z. \& Elbein, S. C. Linkage and association mapping of a chromosome 1q21-q24 type 2 diabetes susceptibility locus in northern European Caucasians. Diabetes 53, 492-499 (2004).

28 Gauderman, W. J. Candidate gene association analysis for a quantitative trait, using parent-offspring trios. Genet. Epidemiol. 25, 327-338 (2003).
29 Mahajan, A., Tabassum, R., Chavali, S., Dwivedi, O. P., Chauhan, G., Tandon, N. et al. Obesity-dependent association of TNF-LTA locus with type 2 diabetes in North Indians. J. Mol. Med. 88, 515-522 (2010).

30 WHO Expert Consultation.. Appropriate body-mass index for Asian populations and its implications for policy and intervention strategies. Lancet 363, 157-163 (2004).

31 Isomäki, P., Aversa, G., Cocks, B. G., Luukkainen, R., Saario, R., Toivanen, P. et al. Increased expression of signaling lymphocytic activation molecule in patients with rheumatoid arthritis and its role in the regulation of cytokine production in rheumatoid synovium. J. Immunol. 159, 2986-2993 (1997).

32 Yang, R. Z., Lee, M. J., Hu, H., Pray, J., Wu, H. B., Hansen, B. C. et al. Identification of omentin as a novel depot-specific adipokine in human adipose tissue: possible role in modulating insulin action. Am. J. Physiol. Endocrinol. Metab. 290, E1253-1261 (2006).

33 de Souza Batista, C. M., Yang, R. Z., Lee, M. J., Glynn, N. M., Yu, D. Z., Pray, J. et al. Omentin plasma levels and gene expression are decreased in obesity. Diabetes 56, 1655-1661 (2007).

34 Schaffler, A., Zeitoun, M., Wobser, H., Buechler, C., Aslanidis, C. \& Herfarth, H. Frequency and significance of the novel single nucleotide missense polymorphism Val109Asp in the human gene encoding omentin in Caucasian patients with type 2 diabetes mellitus or chronic inflammatory bowel diseases. Cardiovasc. Diabetol. 6, 3 (2007).

35 Ong, K. L., Leung, R. Y., Wong, L. Y., Cherny, S. S., Sham, P. C., Lam, T. H. et al. Association of F11 receptor gene polymorphisms with central obesity and blood pressure. J. Intern. Med. 263, 322-332 (2008).

36 Gao, F., Zhang, R., Hu, C., Fang, Q. C., Wang, C. R., Ma, X. J. et al. Association of $6735 \mathrm{~T} \rightarrow C$ variant of glucokinase-associated dual-specificity phosphatase 12 gene with type 2 diabetes in Chinese. Zhonghua Yi Xue Za Zhi 88, 2250-2253 (2008).

37 Thameem, F., Farook, V. S., Bogardus, C. \& Prochazka, M. Association of amino acid variants in the activating transcription factor 6 gene (ATF6) on 1q21-q23 with type 2 diabetes in Pima Indians. Diabetes 55, 839-842 (2006).

38 Meex, S. J., van Greevenbroek, M. M., Ayoubi, T. A., Vlietinck, R, van Vliet-Ostaptchouk, J. V., Hofker, M. H. et al. Activating transcription factor 6 polymorphisms and haplotypes are associated with impaired glucose homeostasis and type 2 diabetes in Dutch Caucasians. J. Clin. Endocrinol. Metab. 92, 2720-2725 (2007).

39 Chu, W. S., Das, S. K., Wang, H., Chan, J. C., Deloukas, P., Froguel, P. et al. Activating transcription factor 6 (ATF6) sequence polymorphisms in type 2 diabetes and prediabetic traits. Diabetes 56, 856-862 (2007).

40 Rosenberg, N. A., Mahajan, S., Gonzalez-Quevedo, C., Blum, M. G., Nino-Rosales, L., Ninis, V. et al. Low levels of genetic divergence across geographically and linguistically diverse populations from India. PLoS Genet. 2, e215 (2006).

41 Indian Genome Variation Consortium.. Genetic landscape of the people of India: a canvas for disease gene exploration. J. Genet. 87, 3-20 (2008).

Supplementary Information accompanies the paper on Journal of Human Genetics website (http://www.nature.com/jhg) 